\title{
Foto-turismo: la constitución social de una mirada persistente
}

Cecilia Fuentes

Universidad de Guanajuato

Resumen

Este artículo explora la visión del citadino y el turista, aficionados por excelencia a la captura y posesión del entorno inmediato y practicantes socialmente condicionados para el ejercicio de la imitación. La ciudad será adoptada como el referente por excelencia del extraviado viandante debido al consagrado decoro y su relativa permanencia. Entre los planteamientos centrales se revisará que: 1) el viaje favorece la actividad fotográfica; 2) la fotografía se convierte en una diligente empresa del viajero; 3) entre los cuidados que debe mostrar se priorizará en la localización y su reconocimiento público; 4) ante el ejercicio fotográfico el turista se valdrá de recetas estandarizadas — seguramente inconscientes-, y 5) en la pretensión de certificar su presencia omitirá la vivencia y su facultad judicativa.

Palabras clave: Turismo, aficionado, ciudad, fotografiable, régimen.

\section{Abstract}

This article explores the vision of the city dwellers and tourist, amateurs by excellence of the capture and possession of the immediate environment and socially conditioned practitioners of the exercise of imitation. The city will be adopted as an obligatory motive to the traveler due to the decorum and its relative permanence. Some of 
the points that will be discussed are: 1) travel promotes photographic activity; 2) photography becomes main motivation of the travelers; 3) some of the priority points are the location of the important spots of the city and focus on the public acknowledgment; 4) tourists will use standardized methods - probably unconscious-, and 5) to attest his presence the tourist might forget his experience and judgmental faculty.

Keywords: Tourism, Amateur, City, Be photographed, Regime.

Un Dios vengador ha atendido a los ruegos de esta multitud. Daguerre fue su Mesías. Y entonces se dice: "Puesto que la fotografía nos da todas las garantías deseables de exactitud (eso creen, ¡los insensatos!'), el arte es la fotografía". A partir de ese momento, la sociedad inmunda se precipitó, como un solo Narciso, a contemplar su trivial imagen sobre metal. Una locura, un fanatismo extraordinario se apoderó de todos esos nuevos adoradores del sol [...]

Charles Baudelaire

Como es sabido Baudelaire le reprochó a la naciente industria En la irrupción y acelerada aceptación del recurso reconoció el gusto, la credibilidad y la acción multitudinaria y consideró que la moderna herramienta sólo sería pertinente para ese uso medial que auxilia en las labores de exactitud. Sin embargo, y parafraseando su texto, Baudelaire posó varias veces con su mueca de circunstancia durante el tiempo que Nadar necesitó para cumplir con la operación. Así, el crítico de la modernidad se convirtió en uno de los célebres modelos del ilustre fotógrafo y en una (varias) imagenretrato de ordinario carácter formal para las masas. 
Desde lo ordinario será tratado el asunto meramente instrumental que nos atañe. Mediante la recuperación de textos claves que sitúan la práctica fotográfica, ${ }^{1}$ examinaremos la actividad ejercida por el turista en sus recorridos citadinos. Para ello, en primer lugar, orientaremos las reflexiones a la disposición circunstancial del aficionado por esos encuadres fotografiables en lugares emblemáticos, recurriendo - frecuentemente- a convencionalismos persistentes; en segundo lugar, una vez consideradas las funciones primordiales y las normas de apariencia, intentaremos acceder a la imagen hecha con una consecuente pérdida de experiencia vivencial y a una ciudad que visualmente se construye uniformada, recursos que no entrarían a discusión sin antes mencionar las pretensiones universalistas del medio en su habla coloquial y una práctica generalizada.

\section{I}

En concesión a la analogía tan propia del medio, me permitiré unas cuantas relaciones: Mientras Van Gogh pintaba girasoles y Gauguin pintaba a Van Gogh pintando girasoles, la fotografía ya

${ }^{1}$ Desde la fotografía seguiremos esta línea básica de pensamiento y para ello tener en mente su temporalidad será fundamental: Baudelaire escribe "El público moderno y la fotografía" en el salón de 1859, la "Pequeña historia de la fotografía" de Benjamin considera hasta 1931, Bourdieu comienza su estudio "Una arte medio" en 1961 y publica en colaboración "El campesino y la fotografía" en 1965, las descripciones "Sobre la fotografía” de Sontag son publicadas en 1973, las consideraciones semiológicas de Barthes aquí consultadas salen a la luz en 1980 y 1982 respectivamente y "Lo fotográfico" de Krauss es publicado en 1990. El resto de autores consultados, en este caso, son referencias importantes para ampliar el esquema central o complementar la línea sugerida. Desde el enfoque otorgado, la ciudad será empleada como un motivo fotográfico de estricta dimensión física, en tanto ciudad fotogénica, de ahí que el pensamiento sugerido no contenga las mismas consistencias formales y amerite una mayor consideración en el futuro. 
era un artificio amigable y con simpatizantes. Lejos de la imagen única con tomas prolongadas e inventores-técnicos altamente especializados, ya habían salido al mercado los aparatos portátiles previstos para la clandestinidad, Kodak emerge garantizando las facilidades de operación y revelado, en pocos meses lanza el modelo infantil e instituye su afamado eslogan "Apriete el botón y nosotros haremos el resto". A pasos agigantados se incorporan públicos y practicantes para el uso concreto de la primaria expresión, en términos semejantes es común suponer que cualquiera es un fotógrafo en potencia.

Para 1888, la incorruptible representación de la fotografía se aplicaba regularmente como un auxiliar de la ciencia y acompanante indispensable en las pesquisas expedicionarias como tomas de altura, aéreas o de profundidades; como registros astronómicos, botánicos o zoológicos de expediente enciclopédico, o bien, como complemento minucioso en el progreso de las enfermedades. En otros terrenos se utiliza como material corriente para proveer de imágenes a los artistas, como recreación arquitectónica y, a partir de los estudios consecutivos sobre la locomoción animal, se cuenta como método fiable para determinar al ganador de las carreras hípicas e incluso, una vez incorporado el método Bertillon, en las ya comunes fotografías de identidad dentro del ámbito judicial. ${ }^{2}$

${ }^{2} 1888$ se reconoce como año ejemplar en la historia de la fotografía porque George Eastman lanza Kodak, aparato portátil, ágil y que incluye en el precio el rollo, el revelado y las copias. Un poco antes las cámaras de naturaleza detectivesca se habían popularizado (ocultas en bastones, bolsas de mano, libros, etc.) y la versión infantil del 1900 instituye ese eslogan de popularidad ampliada. Desde la década de los cincuenta, el servicio de la herramienta se difundió para abastecimientos científicos por su pretendida objetividad mecánica, Muybridge trabaja con las secuencias desde los setenta pero perfecciona y amplía la serie para los ochenta (Keim, 1971; Johnson, 2012). Desde 1882 comienza el uso regular de las fotografías al servicio de la identidad judicial creado por el funcionario de policía parisino Alphonse Bertillon. Utilizado como sistema para 
En el tercer decenio del siglo XX y con mayores fortalezas teóricas para la asimilación de la práctica — ahora ni tan nueva, ni tan única-, Walter Benjamin se pronunciará como entusiasta precursor de la historia fotográfica, volviéndose además un analista puntual de las formas, técnicas y sentidos variables. El brevísimo texto de 1931 antecede el discurso de la caída del aura y enuncia los alcances del medio revolucionario: la cercanía que permite la apropiación del objeto por su reproductibilidad privilegiando, en consecuencia, el valor de exposición. El portavoz vanguardista pone en evidencia el ofrecimiento público y a gran escala de las tecnologías de la mirada rápidamente desarraigadas, sujetas a convencionalismos y de hechura colectiva (Benjamin, 1989). Si en El autor como productor (Benjamin, 2004) se diluyen las diferencias entre el literato y su público, podríamos sospechar que en el novedoso campo disciplinario habrá poca excepcionalidad de operación, de origen.

Nuestra sospecha por ningún motivo deberá ser comparada con territorios delimitados de subversión o confundida con elucidaciones artísticas, de ser así caeríamos en esas incansables suposiciones donde se asume que todo aquel que sabe escribir puede hacer literatura y que todo aquel que porta una cámara hace fotos. De hecho, ya que las observaciones se centrarán en el ámbito de lo común como una de las múltiples versiones existentes, permítaseme hablar a partir de ahora de tomar fotos, en esa facultad de arrancar un extracto de la realidad y no tanto de una acción constructiva a partir de ella, en exclusiva concesión a la tiranía analógica como la llama Regis Durand (2012) y en el estado literal de Roland Barthes (2009), donde habitualmente — debido a los procesos físico-químicos y mecánicos- se asume la casi total

identificar delincuentes o hacer expediente de los detenidos y sospechosos, el bertillonage o retrato hablado consistía en la medición antropométrica y fotografía del individuo de frente y perfil que se pegaban a la tarjeta que llevaba por nombre el de su inventor (Agamben, 2011: 66). 
exclusión de la participación humana enalteciendo la lógica del médium.

La fotografía así entendida será sometida a su interpretación más obscena, como un encuadre de realidad que es tributario del dispositivo técnico que lo retiene y se arraiga en la insistencia de mostrar lo que se vio en un momento dado; será reducida a su carácter de documento de lo evidente en forma estrictamente indicial, genéticamente dice Rosalind Krauss: "Se sitúa del lado de las huellas de manos, de las máscaras mortuorias, del sudario de Turín o de las huellas que las gaviotas dejan sobre la playa" (2002: 120), y reforzará la posición del agente que está provisto de un mundo acumulable en imágenes, quien se apega fanáticamente a la analogía e insiste en las semejanzas que manifiesta su co-presencia sustancial e insustituible con el referente y almacena ilustraciones sobre su verdadero trayecto por la vida y cuestiona la pérdida de sus instantes. La dimensión fotográfica aquí expresada se restringe a una sola de las tareas asignadas: a la actividad democrática, de reconocida afición que se practica como suplemento de anécdota y como prótesis que usurpa la experiencia del observador.

\section{II}

Los relatos de viaje preceden a la fotografía en inclinación pública, lo mismo que los diarios y bitácoras asociadas a los desplazamientos espaciales, ellos, sin embargo, en su complejidad y simpleza, se resolvían como interpretaciones subjetivas sobre la vivencia del escribano. De manera similar ocurre con las representaciones visuales, muchos viajeros evitaban largas descripciones situacionales al ejercer la práctica de trazar bocetos de los sitios visitados con ayuda de la cámara oscura, otros más — por temor a la incredulidadhacían levantamientos intuitivos de carácter arqueológico. Duran- 
te el siglo XIX, se consolidan las ampliamente difundidas vedutas o vistas de tradición ilustrada que de forma detallista accedían al paisaje — normalmente urbano- con la suficiente fidelidad y exhortación de realidad requerida, término que ampliado además se utilizó posteriormente para denominar las tarjetas duales de vista estereoscópica con requisitos idénticos: terrenos proclives al efecto de profundidad con tomas alejadas, de paternidad colectiva y específicamente paisajística.

El apego por catalogar un sistema geográfico con la distribución y estilo de vida de los europeos citadinos era una práctica tan difundida que, tal como alude Krauss, las vistas se confinaban a un cajón expresamente ideado para ello como parte del indispensable mobiliario burgués del XIX (Krauss, 2002). Una vez que se simplifican los procesos de laboratorio, la fotografía comienza a usurpar y satisfacer las necesidades públicas de retratar el exterior. La historia de la fotografía atiende asiduamente a personajes específicos que se dieron a la tarea —oculta o evidente- de hacer un registro de la ciudad desde el exotismo que promovía o desde la colonización que exigía. ${ }^{3}$ En algunos casos se afianzaba como registro de conservación y transformación de monumentos para fines de restauración o de recuento patrimonial, en otros como evidencia y justificación de lo que determinados regímenes construían, caso expreso del Porfiriato mexicano.

El registro de la ciudad promovía la certeza propia del aparato fotográfico, pero asegurando — en la medida de lo posible_ la in-

${ }^{3}$ Como contexto y referente, entre los fotógrafos multicitados por la historia que concedieron, en un principio, el lugar privilegiado y de distinción al registro de la ciudad, están, en Francia: el viajero Maxime Du Camp (1822-1894), Gaspard-Félix Tournachon —seudónimo Nadar- (1820-1910), Jean Eugéne Auguste Atget (1856-1927), Gyula Halasz — posteriormente- Brassaï (18391984); en Inglaterra y sus alrededores: John Thomson (1837-1921); en Estados Unidos: Arnold Genthe (1869-1942), Alfred Stieglitz (1864-1946), Arthur H. Fellig — conocido como Weegee - (1899-1968), Berenice Abbott (1898-1991). 
variabilidad del referente, cosa que no ocurría con modelos vivos a quienes se les determinaba una pose o guión de comportamiento. Susan Sontag describe cómo, entre los integrantes del Farm Security Administration, (comisionados norteamericanos para dejar constancia de los desfavorecidos campesinos de los años treinta), se realizaban un sinnúmero de tomas hasta respaldar la visión de pobreza que el fotógrafo debía expresar (2013). Debido a la condición emplazada de la estructura arquitectónica, a la asociación con programas de estudio social y muestreo del entorno, no es de extrañar que la ciudad se adopte como tema sugerente y de tradición obligada, tampoco lo será, que entre las evoluciones de la tecnología fotográfica se le diera una agilidad especial a los complementos de la visión panorámica.

Como portador de una especial sensibilidad urbana, Sontag aludirá al aspecto vital del flâneur, personaje histórico equiparable a la cámara en su extensión de mirada:

El fotógrafo es una versión armada del paseante solitario que explora, acecha, cruza el infierno urbano, el caminante voyerista que descubre en la ciudad un paisaje de extremos voluptuosos. Adeptos a los regocijos de la observación, catador de la empatía, al flâneur el mundo le parece pintoresco [...] no le atraen las realidades oficiales de la ciudad sino sus rincones oscuros y miserables, sus pobladores relegados, una realidad no oficial tras la fachada de vida burguesa que el fotógrafo aprehende como un detective aprehende a un criminal (Sontag, 2013: 61-62).

Esta primera mirada despierta, particularizada y ejemplar comulga con las búsquedas apartadas del Atget de Benjamin y las asociaciones que hace de sus fotos con el lugar de un crimen. El viandante por excepción, sin embargo, pertenece a ese minúsculo grupo de disidentes que — si acaso se incluyen en esta revisión- es por volverse paradigmas formales de la subsecuente tipificación. 
Una vez que los desplazamientos metropolitanos sincronizaron sus apetencias con la sensación ubicua de la cámara, aficionados e industria coincidieron también en prácticas activas. Kodak —narra Sontag a propósito de la agilización de los medios de transporte estadounidenses - colocaba letreros claves en las fronteras poblacionales para hacer las recomendaciones necesarias de los sitios fotografiables y de los lugares idóneos dentro de ellos para hacer las tomas (2013). La documentación fotográfica realizada por encargos administrativos no sólo recogía un amplio bagaje de los espacios, personas y situaciones que configuraban a los estados nacientes, sino que finalmente estos hacían compendios de identificación sobre los lugares representativos de las localidades en construcción. En la Revolución Mexicana, por ejemplo, se introducen aspectos de dinamismo técnico y social dentro de la vida urbana, por lo que no sólo se le atribuirá el valor de reportaje sino de crónica visual sobre los aspectos complejos y significativos del territorio.

Para Pierre Bourdieu, la generosa expansión de la práctica fotográfica se ve privilegiada por la figura del citadino clase-mediero, quien consagra su estatus de civilidad encontrando aficiones relativas a la urbe profana: observaciones del continuo progreso, así como el disfrute del espacio y posibilidades agrandadas de desplazamiento turístico. En la pretensión de buscar la distinción del campesino es que la clase media muestra mayor devoción y potencia para ejercer la labor. El campesino, por su parte, consigna la ocasión de fotografiar los acontecimientos sociales de revitalización grupal, siendo originalmente las bodas la festividad más respetable para ese tipo de despilfarro ostentoso. Mientras los rurales consagran su consumo (no productivo) al ritual y al lujo, los habitantes de la ciudad se afianzan en una actividad frívola que complementa sus vidas, demostrando su éxito social con la posesión de la cámara y con las múltiples actividades de las que 
participa para ejercer la práctica, que va, desde el relato familiar y el crecimiento de los hijos hasta el registro de los logros personales (Bourdieu, 2003 y 2010). ${ }^{4}$

Si como asume Bourdieu en su revisión sociológica, al citadino se le ha asignado la labor social de fijar las riquezas de su entorno, al veraneante se le condicionará a probar y justificar su movimiento, tal como lo entiende, porque su situación financiera lo permite,

${ }^{4}$ Las ideas de Bourdieu aquí expresadas tienen la pretensión de servir como detonantes reflexivos para los objetivos del artículo, principalmente la ubicación de los agentes en circunstancias específicas: el turista, el citadino clase-media, el campesino y, posteriormente, las razones sociales que dichos personajes encuentran en la existencia de la fotografía para su uso convencional. Cabe destacar, sin embargo, que el estudio de Bourdieu tiene orígenes empíricos y delimitaciones concretas relacionadas con la historia del texto: 1) es un encargo de aspiraciones estadísticas realizado por Kodak-Pathé a Raymond Aron, quien finalmente lo delega al treintańero Bourdieu, mismo que organiza un prudente equipo de trabajo; 2) las intenciones originales del encargo son modificadas ante la libertad exigida por sus investigadores, comenzando como un estudio del impacto social de la fotografía y ampliándose a la consulta de un fenómeno con condiciones de práctica social generalizada sin perder los matices del enfoque; 3) el encargo se realiza en 1961 y el texto se hace público hasta 1965, aunque el estudio es predominantemente francés, Bourdieu particulariza aún más situando sus observaciones en una aldea rural de la región de Béarn de la que es oriundo y desde la cual determina ciertas condiciones campesinas, además centra su análisis en el historial fotográfico de Jeannot residente y amigo personal, evidentemente las asociaciones de aspiración urbana también serán relacionadas desde aquí, y 4) las preocupaciones de Kodak por comprender el fenómeno social que tenía entre manos podrá darnos pautas sugerentes, las invenciones cercanas al contexto incluían la coloración y la instantaneidad fotográfica, además que la década de los sesenta se decanta por otorgar un servicio más a la práctica fotográfica, cumpliendo una modalidad de registro objetivo de las actividades poco objetuales del arte debido a su énfasis procesual o conceptual. Para ampliar los elementos aquí expresados conviene leer con singular apremio el elocuente prólogo realizado por Antoni Estradé para "Un arte medio" y, finalmente, conviene delimitar los contenidos sin que ello signifique poner un límite a sus implicaciones y pertinencia presente. 
pero sobre todo, por el reforzamiento del lazo familiar que implica la excepción de la circunstancia y la necesidad de solemnizarla (Bourdieu, 2003). La alianza entre fotografía y turismo quedará sellada rápidamente ante la socialización normalizada del dispositivo y el incremento habitual de los desplazamientos que necesitan ser reportados en su periodicidad. Baudelaire ya había confinado a los daguerrotipistas a enriquecer con precisión el álbum del viajero y Benjamin dejaría planteada la divisa general del registro: "El mundo es hermoso" (Benjamin, 1989: 80).

Las razones expresadas por Sontag quizá sean las más convenientes para el caso: viajar se convierte en el pretexto idóneo para tomar fotos y ampliar el acervo de sus colectores, de forma estratégica se realiza una posesión imaginaria del espacio público que provoca inseguridad entre sus visitantes; por una parte, puede mitigar la desorientación en el lugar que sobrepasa, por otra, puede proveer al inquieto turista de una tarea rigurosa que aminore la angustia por verse privado de su territorio y faena rutinaria. ${ }^{5}$ Entre los privilegios del portador de la cámara están el dominio y la posesión simbólica, la cámara finalmente es una herramienta de control (Barrios, 2010) y como tal ejerce una dependencia con su usuario. Mucho se ha dicho sobre el poder asesino y dignificado de la cámara, pero también de la falta de sutileza léxica con la que nomina su proceder: la cámara (analógica) se empuña, carga, apunta y dispara; el camarógrafo ve por la mirilla, aprieta el disparador; el modelo es el blanco; se habla — sobre todo con la digitalizaciónde ráfaga de fotos o efecto ametralladora.

5 "Alto, una fotografía, adelante. El método seduce sobre todo a gente subyugada a una ética de trabajo implacable: alemanes, japoneses y estadounidenses. El empleo de una cámara atenúa su ansiedad provocada por la inactividad laboral cuando están en vacaciones y presuntamente divirtiéndose. Cuentan con una tarea que parece una simpática imitación del trabajo: pueden hacer fotos [...] poseer una cámara ha transformado a la persona en algo activo, un voyeur: sólo él ha dominado la situación” (Sontag, 2013: 20). 
El viaje se convierte en un safari fotográfico del lugar que se habita provisionalmente, pero para hacer constar la presencia será fundamental llevar un registro minucioso de lo identificable. Así, para los fotógrafos de excepción, el objetivo explora campos de experiencia inéditos; en cambio, para los fotógrafos aficionados o foto-turistas, como se les llama despectivamente, el objetivo troza una realidad reconocible de lo que pudo haber sido una experiencia inédita. Me explico y adelanto: 1) el viaje favorece la actividad fotográfica; 2) la fotografía se convierte en una diligente empresa del viajero; 3) entre los cuidados que debe mostrar se priorizará en la localización y su reconocimiento público; 4) ante el ejercicio fotográfico el turista se valdrá de recetas estandarizadas — seguramente inconscientes_- y 5) en la pretensión de certificar su presencia probablemente omitirá la vivencia y su facultad judicativa.

Hasta ahora el primer y segundo enunciados han quedado más o menos resueltos con la ostentación de una clase social, el fortalecimiento de la unión familiar extra-ordinaria, el control o apoderamiento del otro espacio y la sustitución de la compulsión laboral e incluso la invasión agresiva sobre el objeto capturado. Ampliando su pertinencia podemos recurrir a la más nostálgica de sus funciones, según Edgar Morin:

La fotografía sirve de recuerdo, y este servicio puede desempeñar un papel determinante, como el turista moderno, que se prepara y realiza como una expedición destinada a traer un botín de recuerdos, fotografías y tarjetas postales [...] La cámara fotográfica enfundada en cuero es como su talismán que lleva en bandolera. Y para ciertos frenéticos, el turismo es una cabalgata entrecortada con múltiples paradas. No se mira el monumento, se le fotografía. Se retrata uno mismo a pie de los gigantes de piedra. La fotografía se convierte en el propio acto turístico, como si la emoción buscada solo tuviera valor para el recuerdo futuro (2001: 26-27). 
Objeto-imagen que se justifica predisponiéndose a la posterior intensificación y adoración de los extravíos momentáneos y que, por si fuera poco, le da un sentido al desplazamiento mismo. Aquí, la vulgata de la fotografía - término de Morin- pareciera consignada a una promesa de memoria, esa facultad que le atribuye José Luis Brea al régimen de producción de la imagen-materia como institución de permanencia; no obstante, en sus términos, la fotografía pertenece a un régimen distinto del ojo técnico y es depositaria, exclusivamente, de la melancolía del devenir-diferente (Brea, 2010). Si por una parte Morin es capaz de asociar la foto (impresa) de bolsillo a la apropiación privada que desencadena potencias afectivas causadas por el recuerdo; Brea, por otra parte, no concibe poderes atribuibles a la cámara y, por tanto, para este autor el viajante seguramente acabará alejándose de su preciada meta. En ninguno de los casos, sin embargo, se derrumba la asumida creencia de que las memorias remotas puedan retenerse en las superficies de las formas.

Para el tercer enunciado habremos de profundizar un poco más en que la tradición establecida por las vistas turísticas no consistía en la prolongación de una práctica documental arbitraria, funcionaba como insistencia de reconocimiento sobre sitios prototípicos de virtud identitaria, histórica o simplemente de exotismo inconfundible, que finalmente confluyeron en estereotipos informativos sobre un espacio y sus superficiales condiciones de vida. Laura González hace mención de los emisarios importados que debían recorrer México para determinar y registrar el escenario que caracterizaría a la nación y posibilitaría la redundancia - hoy bien conocida- del motivo y el encuadre. ${ }^{6}$ En la imaginería fotográfica

6 "Los fotógrafos que en el siglo XIX trabajaron en México fueron europeos, sobre todo franceses como Louis Plélier, Désiré Charnay, Francois Aubert y Alfred Biquet, entre los más destacados. Asociados a programas de estudio arqueológico, topológico o antropológico, así como a proyectos industriales o 
del XIX nos encontramos con la reiteración constante de ubicaciones geográficas con sus respectivos panoramas urbanos: idénticas edificaciones, zonas y recursos.

No es de extrańar que a partir de los idearios visuales trazados por las naciones para representarse a sí mismas, las ciudades se confeccionaran en función a sus componentes representativos y se anclaran a una versión fotográfica de su apariencia más ordinaria. A partir de estas estructuras condicionadas el turista se ve obligado a retratar los distintivos del lugar y se le juzgará de no hacerlo, su visita queda certificada y justificada si ve y deja constancia de aquello que tenía la responsabilidad de ver, no importando el resto de sus desplazamientos. Recordemos que cliché hace referencia al negativo y al lugar común que aquí manifiesta sus múltiples usos. El turista encuentra su misión haciendo souvenirs de las fotos, convertido en el oportunista que captura la inmediatez de una ocasión, un lugar a través de sus objetos y ocasionalmente al visitador copresente; cuando su labor se restringe al turismo aparece la "sólo fotografía de lo fotografiable" (Bourdieu, 2013: 79).

Podríamos suponer que la carencia de referentes culturales haría mella en un despistado visitante, pero no debemos subestimar el poder de la multi-reproducción de la imagen, del régimen escópico y sus delimitaciones tradicionales. Además siempre habrá elementos que garantizan la igualdad del motivo fotográfico: las agencias de turismo se especializan en excursiones programadas a lugares

comerciales, los fotógrafos viajeros recorrieron el territorio nacional en busca de motivos arquitectónicos, paisajes urbanos y monumentos arqueológicos que identificarían visualmente al país naciente" (González, 2007: 14). Agrega más tarde: "El paisaje fue también uno de los géneros fotográficos más socorridos en el siglo XIX. Aunque la geografía de México es muy variada, el imaginario del paisaje también tendió al estereotipo: paisajes desérticos con magueyes y nopales, panoramas majestuosos de enormes volcanes, vistas selváticas frondosas e impenetrables" (2007: 17). 
atractivos y con multiplicidad de zonas distintivas para un público masivo; las tarjetas postales preservan la integridad de las vistas, el estatus de presencia que ansía el turista y se valen de las estrategias de identificación más convencionales y abarcantes, por ejemplo, reconocemos España por la "Casa Batlló” de Gaudí en Barcelona, Italia por el "Coliseo" romano, México por "El Castillo" de Chichén Itzá en Yucatán, etc.; las genéricas guías turísticas, dice Bourdieu: "Se convierten en una llamada constante a la admiración, en un manual de percepción bien surtido y dirigido" (2013: 75); por último, el guía alienta la toma en la zona a fotografiar —a veces incluso, el ángulo y momento preciso- proveedor también de la anécdota que acompañará a la fotografía cuando retorne y sea consumida por el otro.

Desde la tesis bourdiana del establecimiento de la función social tendremos las pautas suficientes para comprender la fuente de las trilladas soluciones visuales que nos interesan:

La fotografía popular pretende consagrar el encuentro único (aunque éste pueda ser vivido por miles de personas en circunstancias idénticas) entre un individuo y un lugar famoso, entre un momento excepcional de la existencia y un sitio importante por su alto contenido simbólico. La ocasión del viaje (la luna de miel), solemniza los lugares por los que se pasa y los más solemnes de entre ellos solemnizan a su vez esa ocasión. El viaje de novios plenamente realizado es la pareja fotografiada delante de la Torre Eiffel, porque París es siempre la Torre Eiffel, y porque el viaje de novios verdadero es a París (Bordieu, 2013: 76).

Si la acción turística es un dato de hazaña extravagante por sí misma que amerita ser fotografiada, una motivación solemne promoverá la instancia por excelencia donde una fotografía podrá y deberá hacerse. Según Bourdieu hay un culto decoroso por las ocasiones en situación, o bien, las grandes ceremonias familiares en tiem- 
po y conexión con el santuario donde se realizan, que ejemplifica con el ritual del casamiento y las infaltables tomas de colocación del anillo o el grupo reunido en el portal del templo. La práctica doméstica a la que se refiere tiene una intención agregada, el reconocimiento planteado y la conmemoración efectiva, las dos dependientes y activamente sustentables. Hemos de reconocer, no obstante, que para el sociólogo la práctica nunca es indefinida y tiene que estar plenamente justificada, de no ser así la foto no se lleva a cabo. El simbolismo del sitio al que se le agrega la pertinencia de la circunstancia (simple turismo o turismo especializado) será siempre un acto digno de fotografiarse tal como asume la ética del aficionado. Es la ideología — asume Sontag — "lo que determina qué constituye un acontecimiento" (2013: 28) y a cuales fragmentos emblemáticos se les concederá la importancia.

Seguramente el turista se siente auténtico en sus elecciones aún cuando vea las cosas de la misma forma que el resto de sujetos que lo precedieron, acompañan o emularán. Abusando del ejemplo: todos los visitantes de París se retratan en la Torre Eiffel, todos los recién llegados buscan la Torre Eiffel para retratarse en ella y todos los consumidores de las fotos del turista se congraciarán en el reconocimiento de la Torre o —en casos rarísimos - pedirán cuentas de su ausencia. Pasemos a nuestra cuarta proposición sobre las recetas estandarizadas, donde ha de suponerse ya que la Torre Eiffel no sería tan distintiva si tuviera alguna variedad en su toma, o bien, no se hubieran hecho menciones sobre encuadres, soluciones formales comunes y sugerencias a condicionamientos de representación (por postales, guías, letreros Kodak, etc.). Para Bourdieu nada tiene mayor reglamentación que la fotografía de aficionados y en sólo una de sus convenciones se enmarca esa necesidad del reconocimiento afianzado.

La práctica fotográfica del turismo, esa a la que específicamente nos referimos, es la práctica de la foto ya hecha, pero ya hecha en 
colectividad por una dudosa paternidad, en primer lugar porque — siguiendo a Rosalind Krauss - se le atribuyó el modelo de la historia del arte $y$, en consencuencia, se hermana con conceptos como el de paisaje con todas las exigencias que el campo había determinado; en segundo lugar, — como prótesis visual de alcances previamente insospechados - se le asignó la labor de encuadrar una realidad que compensara las incapacidades del ojo humano; en tercer lugar, el proceso automático acaba por automatizar las elecciones y formas que finalmente afianzarán un simulacro de la autenticidad (Krauss, 2002). Cuando la fotografía es utilizada como demostración de algo efectivamente ocurrido —el viaje en nuestros parámetros - ésta tendrá que seguir los imperativos objetivos de la demostración, decía Barthes que la fotografía (purista) no puede intervenir en el interior de la imagen como garantía mecánica de la confrontación con su objeto (2009), pero quizá sea la cualidad duplicadora de la maquinaria fotográfica la congruencia esencial para asumir su voluntaria repetición.

Retomando a Bourdieu y los cánones que implica la práctica, deben ser mencionadas la frontalidad y centralidad como formatos activos en el reconocimiento de los objetos fotografiables. Según su explicación, al objeto se le atribuye un valor efectivo si utiliza el recurso de la composición axial, el encuadre enmarca el monumento desde una toma delantera que omite toda ambigüedad de reconocimiento y, en la mayoría de los casos, se considerará la distancia pertinente para comprender la captura íntegra del referente principal, una vez reunidos los factores indispensables podrá (o no) ser incluido un minúsculo personaje que requiera de nominación posterior para ser situado en el espacio. En la apuesta del turista se renuncia a la toma cercana de difícil comprensión y se siguen los esquemas de la llamada visión normal o natural (por supuesto de evidente selección convencional), entre ellas, para los que posan en solitario o grupo: mirada frontal, cohesión entre los personajes y sonrisa o frase célebre; para el que toma la foto se siguen las pro- 
hibiciones de manual reglamentarias: quietud, seguir la línea de horizonte y jamás fotografiar a contraluz (Bourdieu, 2003).

Es verdad que entre los abastecimientos primitivos del dispositivo se consideran el primer plano y la detección remota tal como es mencionado por Sontag y que los efectos composicionales determinan no sólo las jerarquías formales de la imagen sino la vista jerarquizada de su observador; sin embargo, tal como es planteado por Bourdieu, la competencia técnica del dispositivo con el que se cuente no determinará — para los aficionados — los resultados visuales, ya que las bondades del aparato desbordarán las necesidades del ingenuo usuario. Aquí, me permito incluir las supuestas ventajas que podría aportar la cámara digital, donde la única variante sería — si acaso- ese recurso ametralladora con el cual se incrementa considerablemente la cantidad de tomas sobre el mismo motivo, propiciando sólo el aumento cuantitativo de accidentes afortunados. En este uso estereotípico en el que lo representado se repite, el registro se limita a crear normas de apariencia y la revolución visual confirma solamente otros hábitos de visión.

En casos particulares de subversión artística, Durand insistirá en el uso de las fortalezas de la evidencia con la pretensión de reivindicar la presencia en la imagen, casos múltiples que en la historia de la fotografía dan muestra de la fascinación por el acercamiento al objeto, el uso de la frontalidad y el primer plano:

Siempre ha habido una tendencia a una máxima captación del objeto fotografiado — la más frontal, la más cercana, la más clara[...] forma de acercarse al objeto al máximo [...] ¿Quizá podría hablarse de objetualidad, como de una cualidad analógica que tiende a aproximar al máximo el simulacro del objeto, como si se tratara de devolver un contenido de presencia a la imagen por medio de la simple fascinación de la cosa representada?" (Durand, 2012: 65). ${ }^{7}$

${ }^{7}$ Entre los casos explorados por Durand, logrados bajo recursos semejantes, cuenta a Blossfeld, Renger-Patzsch y Walker Evans; en la fotografía contempo- 
En nuestro caso, sometidos exclusivamente a la irrisión del afán documental sin fuerza y a la posición dominante, podemos concebir este modo como una predisposición a la igualdad de factura colectiva. Pensemos que cuando - rara vez- una imagen sale de lo convencional o rompe con el decoro esperado, cuestionamos: ¿quién la hizo?

Vayamos a la quinta y última proposición sobre la omisión de la vivencia del turista. En singular mención y refiriéndose al foto-reportero, Susan Sontag dirá: "Situaciones en las cuales el fotógrafo debe optar entre una fotografía y una vida, opta por la fotografía. La persona que interviene no puede registrar; la persona que registra no puede intervenir" (2013: 21). En este caso límite se explora la fotografía en su aspecto más pasivo aún sin serlo, el periodista alienta la continuidad de la acción que testimonia y permite su continuidad, en la compulsión turística ocurrirá algo similar, el testigo del paraje, comisionado socialmente para llevar el vestigio de su visita, buscará aquello que reconoce (vegetativamente) promoviendo la fijeza de su objeto, no sólo en imagen latente, ya que de su foto dependerá que otros re-fotografíen lo mismo tal como él lo hizo. Al estar más consternado por la ejecución de la fórmula y el apaleamiento de sus malestares psicológicos, el turista de Sontag sustituirá su experiencia por el acto mismo de fotografiar y por el hecho de ver su motivo como fotografía.

El referente mismo se miniaturiza y aplana, es del tamaño de la mira o pantalla y no tiene peso, prominencias, curvas, huecos o continuidad. La cámara amplía pero usurpa la observación, debilita la presencia por el instrumento y con la democratización

ránea considera a Valérie Belin, Gunther Förg, Patrick Tosani, Bernd y Hilla Becher, Thomas Ruff y Roland Fischer (los últimos cuatro como vistas fijas y temporales de la arquitectura $\mathrm{o}$ - para sus herederos conceptuales - como vistas fijas de retrato en frialdad descriptiva). 
del aparato y de la experiencia se fomenta la burla póstuma: las fotografías tomadas durante el viaje — pese a su inevitable presencia-son la experiencia visual primaria y el ex-turista contemplará en casa, por primera vez, lo que debió haber sido la versión portátil y secundaria de un acontecimiento solemne. El viajero no necesita las coartadas del foto-periodista, ni se funde ni se implica, no ve más que clichés. El turista de Bourdieu seguirá una línea similar, es un impenitente agotado de la búsqueda operativa que no mira su referente. Aún en este caso, desvinculándome de las consideraciones bourdianas, puedo asumir que la pertinencia estética es relevada a un tercer plano de importancia, ya que el encuentro con el objeto se aplaza, primero porque, en la consecución deberá satisfacer los imperativos que lo condicionan (y sólo a ellos); segundo porque, con el resultado fotográfico, sólo saciará el encuentro intelectualista de saberse presente en el espacio sin otorgar presencia a la imagen y clausurando la facultad judicativa.

Como ya vimos, el turista de Morin querrá dejarse poseer por la fotografía una vez que haya pasado el tiempo prudente para fetichizar la ausencia del instante que fue y, quizá, ni siquiera considere las carencias vivenciales en el momento. Mas esta pretendida restitución no le devolverá la presencia temporal o espacial, sino el indicio de una doble ausencia: la de la experiencia pasada y la de su atención. De interesarnos la hipótesis barthesiana, aquella donde considera que el mensaje del foto-periodismo es —en gran probabilidad - connotado por las convenciones operativas e imposiciones de sentido (Barthes, 1986), quizá acabaríamos por asumir que la fotografía turística está condenada a la connotación, debido a los procedimientos, a los códigos históricos y a los estereotipos de significación cultural. En esa revisión futura, sin embargo, se acabaría por revertir sus capacidades al consagrarse como índice y, aún si la codificación fuera posible, la práctica aficionada tendría que restringirse a una actividad institucionalizada sobradamente 
significante pero no necesariamente estética, porque atendería una función socio-cultural específicamente asignada de carácter histórico, que se vincularía más a un inventario de la realidad con lenguaje expresamente fotográfico de ámbito cognoscitivo; y porque al final, acabaríamos por profesionalizar la práctica informal.

Vayamos por último con nuestro motivo circunstancial: la ciudad, que en este caso, cobra virtudes fotogénicas. En términos llanos aludiríamos exclusivamente a presentarla como objeto-obra que se predispone para su acentuación y embellecimiento, pero en la concepción expandida propuesta por Morin podemos indicar el provecho que se le puede sacar a su orgánica conformación, a despertar su atribuida cualidad pintoresca o remitirnos a lo que de suyo está en el objeto y lo que el sujeto pone en ella. Para nuestros propósitos, sobre todo, habremos de considerar — en la fotogenia de la ciudad - esa exaltación de lo que es valorado y sobrevalorado culturalmente, ese reflejo que nos devuelve lo mismo y esa fijación de los aspectos invisibles para el ojo (Morin, 2001). Su ser fotogénico incluye los estereotipos de identificación y reconocimiento planteados, la duplicación de una visión colectiva afianzada por una lógica de visión y una comprensión teórica de la verdad y, no solamente, la aptitud desarrollada de la visión sobre un referente relativamente fijo, sino el registro del inconsciente óptico, irreflexivo y de fácil captura. Así como el turista acentúa, embellece, saca provecho de su conformación y despierta sus cualidades pintorescas, la ciudad acaba por conformarse en asociación a lo que la fotografía turística le dicta, le acentúa, le embellece y le despierta. Culmina, en fin, comprometida con las fotos que se han hecho de ella. 


\section{Bibliografía}

Agamben, Giorgio, 2011, "Identidad sin persona", en Desnudez, $2^{a}$ ed., Mercedes Ruvituso y María Teresa D’Meza (trad.), Múrcia, Anagrama, Argumentos núm. 427, pp. 63-73.

Barrios, José Luis, 2010, Atrocitas fascinans: Imagen, horror, deseo, México, Rastro blanco.

Barthes, Roland, 1986, "El mensaje fotográfico", en Lo obvio y lo obtuso -Imágenes, gestos y voces-, C. Fernández Medrano (trad.), Barcelona, Paidós, Comunicación núm. 138, pp. 1127.

2009, La cámara lúcida - Nota sobre la fotografía-, Joaquim Sala-Sanahuja (trad.), Barcelona, Paidós, Biblioteca Roland Barthes núm. 4, Barcelona.

Baudelaire, Charles, 2005, "El público moderno y la fotografía", en Salones y otros escritos sobre arte, Carmen Santos (trad.), Madrid, La balsa de la Medusa, núm. 83, pp. 229- 233.

Benjamin, Walter, 1989, "Pequeña historia de la fotografía", en Discursos interrumpidos I -Filosofia del arte y de la historia-, Jesús Aguirre (trad.), Buenos Aires, Taurus, pp. 61-83.

, 2004, El autor como productor, Bolívar Echeverría (trad.), México, Itaca.

, 2009, "La obra de arte en la época de su reproductibilidad técnica", en Estética y política, Tomas Agustín Bartoletti y Julián Manuel Fava (trad.), Buenos Aires, Las cuarenta, pp. 83-133.

Brea, José Luis, 2010, Las tres eras de la imagen: Imagen-materia, film, e-image, Madrid, Akal, Estudios Visuales núm. 6.

Bourdieu, Pierre, 2003, Un arte medio - los usos sociales de la fotografia-,Tununa Mercado (trad.), Barcelona, Gustavo Gili. 
, y Marie-Claire Bourdieu, 2010, "El campesino y la fotografía”, en El sentido social del gusto, Alicia Gutiérrez (trad.), Buenos Aires, Siglo XXI , pp. 51-63.

Durand, Régis, 2012, La experiencia fotográfica, Glenn Gallardo (trad.), Oaxaca, Ediciones Ve.

González, Flores Laura, 2007, Fotografías que cuentas historias, México, INAH / Lumen / Conaculta.

Johnson, William S., et al., 2012, Historia de la fotografía -De 1839 a la actualidad-, Carme Franch y Millán González (trad.), Barcelona, Taschen.

Keim, Jean A., 1971, Historia de la fotografía, Eduard Pons (trad.), Barcelona, Oikos-tau, ¿Qué sé? núm. 52.

Krauss, Rosalind, 2002, Lo fotográfico - Por una teoría de los desplazamientos-, Cristina Zelich (trad.), Barcelona, Gustavo Gili.

Morin, Edgar, 2001, El cine o el hombre imaginario, Román Gil Novales (trad.), Barcelona, Paidós, Comunicación núm. 127.

Sontag, Susan, 2013, Sobre la fotografía, Carlos Gardini (trad.), México, Gandhi, De bolsillo núm. 211.

(Artículo recibido el 4 de enero de 2014; aceptado el 25 de febrero de 2014) 